\title{
Cuticular hydrocarbons on old museum specimens of the spiny mason wasp, Odynerus spinipes (Hymenoptera: Vespidae: Eumeninae), shed light on the distribution and on regional frequencies of distinct chemotypes
}

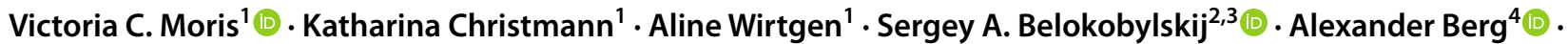 \\ Wolf-Harald Liebig ${ }^{5} \cdot$ Villu Soon $^{6}$ D $\cdot$ Hannes Baur ${ }^{7,8} \cdot$ Thomas Schmitt $^{9}$ (D) Oliver Niehuis $^{1}$ (D)
}

Received: 8 October 2020 / Accepted: 2 April 2021 / Published online: 22 May 2021

(C) The Author(s) 2021

\begin{abstract}
The mason wasp Odynerus spinipes shows an exceptional case of intrasexual cuticular hydrocarbon (CHC) profile dimorphism. Females of this species display one of two CHC profiles (chemotypes) that differ qualitatively and quantitatively from each other. The ratio of the two chemotypes was previously shown to be close to 1:1 at three sites in Southern Germany, which might not be representative given the Palearctic distribution of the species. To infer the frequency of the two chemotypes across the entire distributional range of the species, we analyzed with GC-MS the CHC profile of 1042 dry-mounted specimens stored in private and museum collections. We complemented our sampling by including 324 samples collected and preserved specifically for studying their CHCs. We were capable of reliably identifying the chemotypes in $91 \%$ of drymounted samples, some of which collected almost 200 years ago. We found both chemotypes to occur in the Far East, the presumed glacial refuge of the species, and their frequency to differ considerably between sites and geographic regions. The geographic structure in the chemotype frequencies could be the result of differential selection regimes and/or different dispersal routes during the colonization of the Western Palearctic. The presented data pave the route for disentangling these factors by providing information where to geographically sample $O$. spinipes for population genetic analyses. They also form the much-needed basis for future studies aiming to understand the evolutionary and geographic origin as well as the genetics of the astounding $\mathrm{CHC}$ profile dimorphism that $O$. spinipes females exhibit.
\end{abstract}

Keywords Cuticular hydrocarbons $\cdot$ Chemotypes $\cdot$ Dry-mounted samples $\cdot$ Collections $\cdot$ Distribution

Communicated by Günther Raspotnig.

Victoria C. Moris

victoria.clara.moris@gmail.com

Oliver Niehuis

oliver.niehuis@biologie.uni-freiburg.de

1 Department of Evolutionary Biology and Ecology, Institute of Biology I (Zoology), Albert Ludwig University Freiburg, 79104 Freiburg, Germany

2 Department of Insect Taxonomy, Zoological Institute Russian Academy of Sciences, Saint Petersburg 199034, Russia

3 Museum and Institute of Zoology Polish Academy of Sciences, Wilcza 64, 00-679 Warsaw, Poland

4 SLU Swedish Species Information Centre, Alma allé 8E, 75651 Uppsala, Sweden
5 Goetheweg 9, 02953 Bad Muskau, Germany

6 Natural History Museum and Botanical Garden, University of Tartu, Vanemuise 46, 51014 Tartu, Estonia

7 Department of Invertebrates, Natural History Museum Bern, Bernastrasse 15, 3005 Bern, Switzerland

8 Institute of Ecology and Evolution, University of Bern, Baltzerstrasse 6, 3012 Bern, Switzerland

9 Department of Animal Ecology and Tropical Biology, Biocenter, University of Würzburg, Am Hubland, 97074 Würzburg, Germany 


\section{Introduction}

The cuticular hydrocarbon $(\mathrm{CHC})$ profiles of insects are generally thought to be species-specific, thus showing qualitative and quantitative differences between species (Bagnères and Wicker-Thomas 2010). Intraspecific $\mathrm{CHC}$ profile differences are most often observed between sexes and between samples from different populations, but $\mathrm{CHC}$ profiles are also known to change with the insect's age, mating and fertility status, diet (Liang and Silverman 2000), and in case of eusocial insects with the individuals caste, task, and colony membership (Sledge et al. 2001; Cuvillier-Hot et al. 2001; Greene and Gordon 2003; Hugo et al. 2006; Jackson et al. 2007; Ichinose and Lenoir 2009; Martin and Drijfhout 2009; Nunes et al. 2009; Blomquist and Bagnères 2010; Kuo et al. 2012; Polidori et al. 2017; Korb 2018). While intersexual CHC profile dimorphism is common in insects, intrasexual CHC profile dimorphism has been found in only a few species, one of which is the spiny mason wasp, Odynerus spinipes (Linnaeus, 1758) (Strohm et al. 2008a, b; Marten et al. 2009; Martin et al. 2010; de Oliveira et al. 2011; Wurdack et al. 2015).

Odynerus spinipes females are able to display one of two $\mathrm{CHC}$ profiles (also referred to as chemotypes) that differ in more than 70 chemical compounds (Wurdack et al. 2015). These qualitative differences are primarily due to the presence or absence of alkenes with double bonds at specific positions (Wurdack et al. 2015). No CHC profile has been recorded so far that was interpreted as intermediate between chemotype 1 and chemotype 2. Odynerus spinipes males only display one chemotype, which is very similar to the females' chemotype 1 (Wurdack et al. 2015).

Wurdack et al. (2015) suggested that the CHC profile dimorphism of $O$. spinipes females is the result of an evolutionary arms race between the spiny mason wasp and two kleptoparasitic cuckoo wasps: Pseudochrysis neglecta (Shuckard 1837) (formerly in the genus Pseudspinolia; Rosa et al. 2017) and Chrysis mediata (Linsenmaier 1951) (Hymenoptera: Chrysididae). Each of the two kleptoparasites seem to chemically mimic one of the two chemotypes. As the two cuckoo wasps are distantly related to each other (Pauli et al. 2019, 2021), they likely evolved their exploitation of $O$. spinipes as host independently from each other. Because Wurdack et al. (2015) found females displaying the two chemotypes to occur sympatrically and observed a balanced (roughly 1:1) frequency of the two chemotypes at all three $O$. spinipes nesting sites that they studied in Southern Germany, the authors hypothesized that the genetic information for expressing the two chemotypes is maintained in $O$. spinipes populations by balancing selection (Wurdack et al. 2015). Given the large distributional range of $O$. spinipes, from Spain in the West to the Pacific coast in the Far East (Gusenleitner 1998; Woydak 2006; present study), the chemotype frequencies determined by Wurdack et al. (2015) are not necessarily representative for the majority of populations of this species, though. Representative sampling of a species with a huge distributional range is often difficult to achieve. A possible solution of this problem could be the exploitation of samples deposited in museum collections.

In this study, we (1) tested if dry-mounted samples of $O$. spinipes that have been collected by entomologists during the last 200 years and stored in private and museum collections carry a sufficient quantity of $\mathrm{CHCs}$ to determine their chemotypes. To this end, we analyzed $\mathrm{CHC}$ extracts of 1042 dry-mounted $O$. spinipes samples using gas chromatography coupled with mass spectrometry (GC-MS). Since $\mathrm{CHCs}$ are, due to their high molecular mass, less volatile and seem to be chemically stable over time (Page et al. 1990; Martin et al. 2009), museum specimens could be a valuable resource for studying $\mathrm{CHC}$ profiles in a biogeographic context. We complemented the data set with 324 freeze-killed fresh samples collected and preserved specifically for studying their CHCs. We further exploited the collected data to (2) test whether the frequency of the two chemotypes of $O$. spinipes females was roughly 1:1 across populations of their distributional range. Since our sampling also included male specimens, we furthermore (3) tested whether $O$. spinipes males displayed consistently only one chemotype. The collected data finally allowed us to assess (4) if $O$. spinipes females with an intermediate $\mathrm{CHC}$ chemotype exist. The reported data form the much-needed basis for studies on the evolutionary and geographic origin as well as the genetics of the astounding qualitative $\mathrm{CHC}$ profile dimorphism of the spiny mason wasp.

\section{Methods and materials}

\section{Samples}

We studied 1,042 dry-mounted wasps stored in the following private or public collections: Deutsches Entomologisches Institut (Eberswalde, Germany; 74 wasps), Museum für Naturkunde (Berlin, Germany, 159 wasps), Naturhistorisches Museum (Wien, Austria; 47 wasps), private collection O. Niehuis (Freiburg, Germany; 173 wasps), Biozentrum of the Oberösterreichisches Landesmuseum (Linz, Austria; 454 wasps), private collection C. Schmid-Egger (Berlin, Germany; 27 wasps), Senckenberg Naturmuseum (Frankfurt a. M., Germany; 44 wasps), Senckenberg Museum für Naturkunde (Görlitz, Germany; 20 wasps), Staatliches Museum für Naturkunde (Stuttgart, Germany; 49 wasps), Zoological Institute of the Russian Academy of Sciences (St. Petersburg, Russia; 52 wasps), Institute of 
Biology and Biomedicine at the Lobachevsky State University (Nizhny Novgorod, Russia; 2 wasps), and Zoologische Staatssammlung (Munich, Germany; 97 wasps). We additionally studied 324 samples collected and directly frozen at $-20^{\circ} \mathrm{C}$ by us at locations in Belgium (105 wasps), Estonia (26 wasps), Southern Germany (167 wasps), and Sweden (26 wasps). Overall, the analyzed samples had been collected between 1826 and 2017 in 22 different countries (Table 1) across most of the species' currently known distributional range (Gusenleitner 1998; Woydak 2006). More information about the samples analyzed, including sampling sites and associated geocoordinates, are provided in the Supplementary Table S1. Note that in those instances in which the label information of samples did not include the geocoordinates of the sampling site, we inferred this information using Google Maps (Google, Mountain View, CA, USA). We analyzed 1366 specimens in total (i.e., dry-mounted and fresh ones), of which 1,009 were females and 357 were males.

\section{Cuticular hydrocarbon extraction}

Females preserved in insect boxes were individually immersed in n-hexane (SupraSolv $n$-hexane for gas chromatography, Merck KGaA, Germany, or Rotipuran $n$-hexane, Carl Roth GmbH, Karlsruhe, Germany) for 2 or for $10 \mathrm{~min}$, depending on the specimen (after analyzing the first batch of dry-mounted specimens, we increased the extraction time from 2 to $10 \mathrm{~min}$ to increase the $\mathrm{CHC}$ yield). All CHC extracts were subsequently reduced to 75 $\mu \mathrm{L}$ by evaporating them under a gentle constant flow of nitrogen. The $\mathrm{CHC}$ extracts were stored at $-20{ }^{\circ} \mathrm{C}$ before proceeding with their chemical analysis. The CHCs of all female wasps collected by us in Belgium (Tenneville) or in Germany (Büchelberg) were either extracted for 10 min with $n$-hexane or were sampled with a solid-phase micro extraction (SPME) fiber (Supelco, coating: polydimethylsiloxane, $100 \mu \mathrm{m}$, Sigma-Aldrich, Bellefonte, PA, USA). Females sampled with SPME fibers were anesthetized either by exposing them for $1 \mathrm{~min}$ to $\mathrm{CO}_{2}$ (females sampled in 2016) or by cooling them for 3 min down at $-20{ }^{\circ} \mathrm{C}$ (females sampled in 2017 and 2018). Conditioned SPME fibers were scrubbed for 2 min against the wasps' metasoma.

\section{Chemical analysis}

GC-MS analyses were conducted with a 7890B gas chromatograph system (Agilent Technologies, Santa Clara, CA, USA) equipped with a DB-5 column ( $30 \mathrm{~m} \times 0.25 \mathrm{~mm}$ ID,
Table 1 Number of female and male wasps analyzed (freshly collected and dry-mounted), collected in 22 countries across O. spinipes species distribution

\begin{tabular}{|c|c|c|c|c|c|c|}
\hline \multirow[t]{2}{*}{ Country } & \multicolumn{3}{|l|}{ Females } & \multicolumn{2}{|l|}{ Males } & \multirow[t]{2}{*}{ Total } \\
\hline & $\begin{array}{l}\text { Freshly col- } \\
\text { lected }\end{array}$ & Dry-mounted & Total & Dry-mounted & Total & \\
\hline Austria & 0 & 150 & 150 & 53 & 53 & 203 \\
\hline Belarus & 0 & 2 & 2 & 0 & 0 & 2 \\
\hline Belgium & 102 & 0 & 102 & 0 & 0 & 102 \\
\hline Bulgaria & 0 & 1 & 1 & 0 & 0 & 1 \\
\hline Czech Republic & 0 & 181 & 181 & 83 & 83 & 264 \\
\hline Estonia & 26 & 3 & 29 & 0 & 0 & 29 \\
\hline France & 0 & 6 & 6 & 0 & 0 & 6 \\
\hline Germany & 170 & 231 & 401 & 166 & 166 & 567 \\
\hline Hungary & 0 & 0 & 0 & 1 & 1 & 1 \\
\hline Italy & 0 & 4 & 4 & 9 & 9 & 13 \\
\hline Kazakhstan & 0 & 2 & 2 & 1 & 1 & 3 \\
\hline Kyrgyzstan & 0 & 0 & 0 & 1 & 1 & 1 \\
\hline Mongolia & 0 & 2 & 2 & & & 2 \\
\hline Poland & 0 & 9 & 9 & 3 & 3 & 12 \\
\hline Romania & 0 & 7 & 7 & 1 & 1 & 8 \\
\hline Russia & 0 & 78 & 78 & 26 & 26 & 104 \\
\hline Slovakia & 0 & 1 & 1 & 4 & 4 & 5 \\
\hline Sweden & 26 & 1 & 27 & 0 & 0 & 27 \\
\hline Switzerland & 0 & 3 & 3 & 2 & 2 & 5 \\
\hline Tajikistan & 0 & 0 & 0 & 5 & 5 & 5 \\
\hline Turkey & 0 & 2 & 2 & 2 & 2 & 4 \\
\hline UK & 0 & 2 & 2 & 0 & 0 & 2 \\
\hline Total & 324 & 685 & 1009 & 357 & 357 & 1366 \\
\hline
\end{tabular}


$d f=0.25 \mu \mathrm{m}, \mathrm{J} \& \mathrm{~W}$ Scientific, Folsom, USA) coupled with a 5977B mass selective detector (Agilent Technologies, Santa Clara, CA, USA), using helium at a constant flow of $1 \mathrm{ml} \mathrm{min}{ }^{-1}$ as a carrier gas. The CHC extracts of ten wasps collected in Tenneville (Belgium) were analyzed with a gas chromatograph-flame ionization detector (Shimadzu GC-2010 system, Shimadzu, Wemmel, Belgium) equipped with a SLB-5 ms non-polar capillary column [5\% phenyl (methyl) polysiloxane stationary phase; $30 \mathrm{~m}$ column length; $0.25 \mathrm{~mm}$ inner diameter; $0.25 \mu \mathrm{m}$ film thickness]. We applied in both instruments the following temperature program: start temperature $40{ }^{\circ} \mathrm{C}$, increased by $10{ }^{\circ} \mathrm{C}$ per minute up to $300{ }^{\circ} \mathrm{C}$, which was maintained for $10 \mathrm{~min}$. The injection port was set at $250{ }^{\circ} \mathrm{C}$ and operated in splitless mode for $1 \mathrm{~min}$. The electron ionization mass spectra were acquired at an ionization voltage of $70 \mathrm{eV}$ (source temperature: $230^{\circ} \mathrm{C}$ ). Total intensity chromatograms and mass spectra were inferred with the software MSD Enhanced ChemStation F.01.03.2357 for Windows (Agilent Technologies, Böblingen, Germany). Individual cuticular hydrocarbons were identified based on their diagnostic ions. To control the sensitivity of the GC-MS, we injected every week and before running a batch of samples a $\mathrm{C} 7-\mathrm{C} 40$ saturated alkanes standard (Sigma-Aldrich, Steinheim, Germany) into the GC-MS.

The two known chemotypes of $O$. spinipes females (de novo identified by Wurdack et al. 2015) were identified by studying the presence/absence of diagnostic alkenes, each of which with a specific retention index. This allowed us to use the GC-MS data from a wide range of samples and independent from the extraction method: $\mathrm{CHC}$ from old dry-mounted specimens extracted with hexane, CHCs from freshly collected specimens extracted with hexane, and CHCs from living specimens extracted with SPME fibers. According to Wurdack et al. (2015), chemotype 1 is characterized by alkenes with double bonds at positions 5,7 , and 9 of the hydrocarbon chain (hereinafter referred to as $u d p$ alkenes), whereas chemotype 2 is characterized by alkenes with double bonds at the positions $8,10,12$, and 14 of the hydrocarbon chain (hereinafter referred to as $e d p$ alkenes). Note that it is easily possible to distinguish the two chemotypes by carefully studying total ion chromatograms and mass spectra, even without derivatization of the CHC extracts: alkenes of chemotype 1 appear at slightly later retention times than the corresponding alkenes of chemotype 2 . The difference is particularly prominent when focusing on the most abundant alkenes on the cuticle of $O$. spinipes females (i.e., those with hydrocarbon chain lengths of 25, 27, and 29; Fig. 1). We nonetheless checked the double bond position of diagnostic alkenes in a subset of samples by sample derivatization applying a custom protocol derived from that given by Dunkelblum et al. 1985 and Carlson et al. 1989. Specifically,

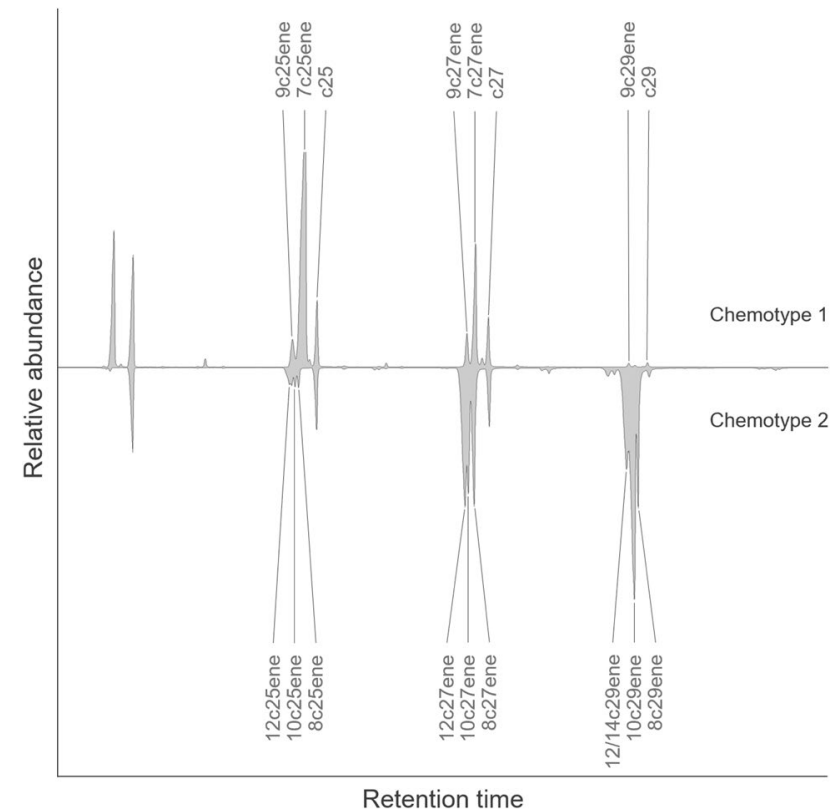

Fig. 1 Chromatograms of frozen sampled CHC extracts of Odynerus spinipes females stored at $-20{ }^{\circ} \mathrm{C}$. The retention time differ slightly between alkenes of females displaying chemotype 1 (top), which have the double bond at an uneven position, compared to alkenes of females displaying chemotype 2 (bottom), which have the double bond at an even position

we inferred the position of double bonds on the cuticle of 146 dry-mounted $O$. spinipes females originating from collections and of $21 O$. spinipes females freshly collected by us in the field. For this purpose, we first concentrated all CHC extract volumes to $120 \mu \mathrm{L}$ each and then mixed each of them with dimethyl disulfide (Merck, Darmstadt, Germany) in a 1:1 ratio. We added to the resulting volume $(240 \mu \mathrm{L}) 85 \mu \mathrm{L}$ of a $5 \%$ iodine solution (Merck, Darmstadt, Germany) in diethyl ether (Merck, Darmstadt, Germany). The reaction volume was thoroughly mixed by hand-shaking it and then kept for $12-24 \mathrm{~h}$ at $60{ }^{\circ} \mathrm{C}$. We subsequently added as many drops of a $5 \%$ sodium thiosulfate solution (Merck, Darmstadt, Germany) in water until the solution turned transparent. Note that the solution was thoroughly shaken by hand after each added drop. Finally, we isolated the organic (upper) phase, transferred it to a new vial, concentrated it under a gentle constant flow of nitrogen, and transferred it into an insert (Agilent Technologies Inc., Santa Clara, CA, U.S.A.; $25 \mathrm{ml}$ glass with polymer feet). The derivatized $\mathrm{CHC}$ extracts were analyzed with the 7890B gas chromatograph system and applying the same instrument settings as described above.

To determine whether or not the quality of $\mathrm{CHC}$ extracts from dry-mounted specimens depended on the number of years between the collection of the specimen and its CHC extraction, we performed a logistic regression with the 
software R version 3.4.1 (R Core Team 2020), using the function glm (Dobson 1990) of the package stats version 3.6.2.

\section{Maps and graphics}

Records of $O$. spinipes females in close spatial proximity to each other were grouped to increase the sample size within a group prior to calculating chemotype frequencies (detailed in the Supplementary Table S1). Specifically, females collected in Central Europe were grouped so that the number of samples under a circle area with $125 \mathrm{~km}$ diameter (covering a surface area of $12,272 \mathrm{~km}^{2}$ ) was maximized (Supplementary Fig. S1). Because regional sample sizes outside Central Europe were typically small, we chose a circle diameter of $420 \mathrm{~km}$ for grouping females collected outside Central Europe. The procedure resulted in a total of 53 groups, 27 of which located in Central Europe (Supplementary Table S2). To visualize the chemotype frequencies in each of the 53 groups, we plotted pie charts and mapped them onto a map of Central Europe and onto a map of the Palearctic region, with the size of the pie charts proportional to the number of female samples included in the respective group. The center of the pie charts is positioned at the location in the circle with the shortest distance to all other locations in the circle. The diameter of the pie charts is the $\log _{10}$ of the number of females in the group. While groups in Central Europe always contained more than two samples, group sizes in the remaining parts of the Palearctic contained in some instances only one sample. To nonetheless be able to visualize these records on the Palearctic map, we added the value 0.5 to all $\log _{10}$ values. The pie chart diameter of groups composed only of one sample was consequently 0.5 and not zero. Note that we divided the $\log _{10}$ values by 4 when plotting pie charts onto the map of Central Europe to reduce the pie charts' diameter. All maps were drawn with the software $\mathrm{R}$ version 3.4.1 ( $\mathrm{R}$ Core Team 2020), using the package "maps" version 3.3.0. Pie charts were plotted onto the maps with the aid of the R package "mapplots" version 1.5.1 (Gerritsen 2013).

\section{Morphometric analysis}

Since we found the CHC profiles of many dry-mounted $O$. spinipes females to display a CHC profile similar to, but differing from that of chemotype 2 described by Wurdack et al. (2015), we conduced morphometric analyses on female samples to assess the possibility that our sampling included a cryptic species. For this purpose, we studied 223 dry-mounted $O$. spinipes females from five different localities, including those at which females with deviant $\mathrm{CHC}$ profiles were recorded. Specifically, we analyzed (A) 28 females from the vicinity of Frankfurt a. M. (Germany; 7 displaying chemotype 1,21 displaying the deviant chemotype 2), (B) 32 females from the vicinity of Leipzig (Germany; 9 displaying chemotype 1, 23 displaying the deviant chemotype 2), (C) 99 females collected in South Bohemia (Czech Republic; 64 displaying chemotype 1, 7 displaying chemotype 2, 28 displaying the deviant chemotype 2), (D) 50 females from the vicinity of Syrovice (Czech Republic; 2 displaying chemotype 1, 48 displaying the deviant chemotype 2), and (E) 14 females collected in the Far East (Russia; all displaying the deviant chemotype 2). We followed the protocol for morphometric analysis given by Wurdack et al. (2015) with slight modifications; specifically, we selected and considered in the final analysis 15 morphological characters from the 16 studied characters based on a reliability test of the characters (see below; Supplementary Table S3, Supplementary Fig. S2). We followed the terminology for naming morphological structures given by Gibson (1997). A list of all quantified morphometric characters is given in Supplementary Table S4.

Each character was photographed with a Keyence VHX 2000 digital photo-microscope and a VH-Z20R/W zoom lens (Keyence, Japan, USA) at different magnifications (30x, $100 x, 200 x)$ depending on the photographed character. To ensure that the magnification did not change between photographs showing the same character in different samples, we conducted all measurements requiring the same magnification in one session without altering the magnification in-between and used an eye-piece micrometer (12 mm subdivided into 120 units; $1000 \mu \mathrm{m}$ corresponded to 888 pixels) to calibrate photographs. To remove additional variation possibly caused by fluctuating asymmetry (Palmer and Strobeck 1986; Bechshøft et al. 2008), we measured characters on the left-hand side, when it was possible. Additionally, we processed the samples in random order to avoid the possibility of systematic errors. All measurements were taken using the software ImageJ version 1.52a (Schneider et al. 2012) on size-calibrated photographs.

Our morphometric analysis consisted of multiple analysis steps. First, we performed a reliability analysis. For this purpose, we aligned and photographed 16 characters in a total of 17 females twice and then calculated measure reliability (which is 1-measurement error, see László et al. 2013) (detailed in Supplementary Table S3). All characters with reliability below $85 \%$ were discarded (one in total). Measurement values of the retained 15 characters in all 223 females samples were studied in a multivariate ratio analysis (MRA) as outlined by Baur and Leuenberger (2011, 2020). We computed an isometric size axis (isosize) and then performed a shape PCA in order to determine whether or not a morphometric pattern corresponds to groups. We also checked measurements for exhibiting allometry by plotting isosize against shape PCs. All statistical analyses were conducted with the software $\mathrm{R}$ version 3.3.3 (R Core Team 2020) and using custom $\mathrm{R}$ scripts provided by Baur 
and Leuenberger (2020). Missing values were replaced by using the function "mice", which applies chained equations, of the R package "mice" and using the function's default options (van Buuren and Groothuis-Oudshoorn 2011). More details on the microscopic photographs, the obtained measurements, and the applied workflow used for imaging and measuring are given in the Supplementary Tables S4 and S5.

\section{Results}

\section{Cuticular hydrocarbons of dry-mounted and of fresh samples}

In 947 of the 1,042 studied dry-mounted wasps (91\%) was the amount of extracted CHCs sufficient to identify the wasp's chemotype (Table 2). Note that our sampling included also 357 males, which consistently showed only one chemotype (similar to the females' chemotype 1). The
CHC extracts of 42 dry-mounted males and 53 dry-mounted females proofed to be insufficient for characterizing their $\mathrm{CHC}$ profile (Table 2). Some of the wasps whose chemotype we were able to determine had been collected almost 200 years ago (the oldest were collected in 1826) (Fig. 2), indicating that even old dry-mounted samples can represent a valuable resource in the field of chemical ecology. We found a statistically significant correlation between the age of the dry-mounted samples and our ability to determine their chemotype (logistic regression, $p$ value $=6.14 \mathrm{e}-06$, Supplementary Fig. S3). However, not all recently collected dry-mounted samples contained a sufficient amount of $\mathrm{CHCs}$ to characterize their $\mathrm{CHC}$ profile and to determine their chemotype (Fig. 2), suggesting that additional factors impact $\mathrm{CHC}$ preservation. In contrast, most of the $\mathrm{CHC}$ samples collected or probed specifically for $\mathrm{CHC}$ analysis (311 out of 324 in total, 13 of which were of insufficient quality, probably because the cold chain was interrupted during
Table 2 Number of freshly sampled and of dry-mounted $O$. spinipes males and females, identified as displaying chemotype 1 ( $\mathrm{c} 1)$, chemotype 2 (c2), deviant chemotype 2 (dev. c2), and the males' chemotype. NA specifies samples whose chemotype remained unidentified

\begin{tabular}{lllllll}
\hline Condition & $\mathrm{c1}$ & $\mathrm{c2}$ & dev. c2 & Male & NA & Total \\
\hline $\begin{array}{l}\text { Freshly sampled } \\
\text { Female }\end{array}$ & 139 & 172 & 0 & & & 324 \\
$\begin{array}{l}\text { Dry-mounted } \\
\text { Female }\end{array}$ & 379 & 7 & 246 & 0 & 13 & 324 \\
Male & 0 & 0 & 0 & 315 & 53 & 1042 \\
Total & 518 & 179 & 246 & 315 & 108 & 1366 \\
\hline
\end{tabular}

Fig. 2 Number of all studied female samples for which the year of collection was known to us $(\mathrm{N}=910$; the year of collection was unknown for 99 female museum samples), identified (left y axis) as chemotype 1 (c1 in orange), chemotype 2 (c2 in purple), and as deviant (deviant c2 in light purple) in different time periods (in years). Unidentified samples are represented in grey (NA). Dry-mounted samples had been collected between 1826 and 2017; freshly collected samples had been collected between 2014 and 2019 . The dark blue line shows the percentage (right $y$ axis) of successfully identified chemotypes in a given time period

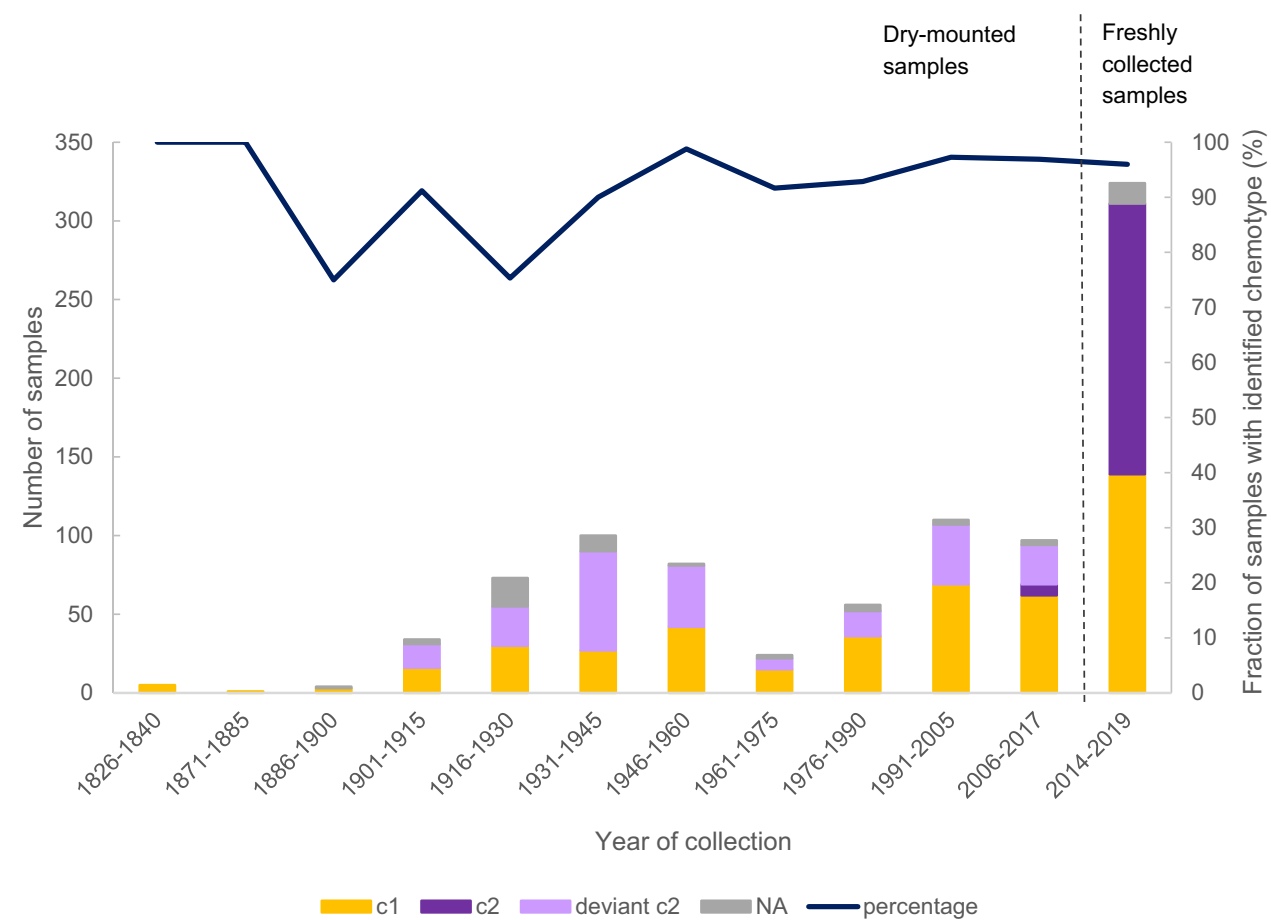


sample shipment; these samples were hence discarded by us; Table 2) were suitable to identify the wasps' chemotype.

We observed a clear separation between the two chemotypes based on the presence and absence of diagnostic alkenes (Fig. 1) in freshly sampled females (CHCs extracted from freeze-killed samples with hexane or with SPME fibers), but not in dry-mounted females. Although we observed exclusively $u d p$ alkenes characteristic of chemotype 1 in 379 dry-mounted females, we observed a mixed chemotype (with $e d p$ and $u d p$ alkenes) in most remaining dry-mounted females. In order to characterize this deviant chemotype, we applied a derivatization protocol to $\mathrm{CHC}$ extracts from a subset of 167 females (Supplementary Table S6). By doing so, we were able to extrapolate the derivatization results to all samples and identify their chemotype (chemotype 1, chemotype 2, or deviant chemotype 2). We found the deviant chemotype 2 in 246 dry-mounted females, but in none of the freshly sampled females (Table 2). In contrast, we found chemotype 2 in 172 freshly sampled females, but only in seven recently collected dry-mounted females (Fig. 2; three collected in 2012 and four in 2017, respectively, by M. Halada and by Z. Haladova).

The derivatization results revealed that the deviant chemotype 2 is characterized by a mix of $e d p$ and $u d p$ alkenes at hydrocarbon chain length 25 and, less frequently, at lengths 23 and 27, depending on the sample. Interestingly, however, we did not find $u d p$ alkenes at hydrocarbon chain length 29 (Supplementary Fig. S4, Supplementary Table S6).

Since none of the freshly collected females displayed the deviant chemotype even in those sampled at locations spatially close to locations from which we had dry-mounded samples with a deviant chemotype 2 profile, it is likely that the deviant chemotype 2 represents an artifact. We hypothesized that it might be the result of long-term storage in museum boxes. Indeed, the few dry-mounted females displaying chemotype 2 had all been collected recently (Fig. 2). Based on this hypothesis, we considered females with a deviant chemotype 2 profile as chemotype 2 for the analysis of spatial differences in chemotype frequencies.

\section{Spatial differences in chemotype frequencies}

We found females of both chemotypes in the Western Palearctic and in the Eastern Palearctic, the presumed glacial refuge of $O$. spinipes, which shows the typical distribution of a Euro-Siberian faunal element as defined by de Lattin (1967). However, we discovered significant geographic structure in the frequency of the two chemotypes, with one chemotype being more frequent in some regions than the other (Fig. 3). For example, we recorded only females of chemotype 1 in western France, the UK, Italy, and the southern parts of Switzerland. In Central Europe, we found a conspicuous North-South gradient in the two chemotype frequencies, with females displaying chemotype 2 being more frequent in the North than females displaying chemotype 1 and vice versa (shift at a latitude of $\sim 49^{\circ} \mathrm{N}$ ). In the South-West of Austria, almost all females sampled show chemotype 1, while in eastern Austria both chemotypes occur at about the same frequency. In the Czech Republic, we found most females displaying chemotype 2, except in regions spatially close to Austria and Poland. Here, females displaying chemotype 1 were more frequent. Interestingly, although the majority of females from northern Central Europe expressed chemotype 2, this chemotype is almost absent at least in parts of Northern Europe (Estonia and Sweden). We found exclusively females displaying chemotype 1 in Kazakhstan, Mongolia, and parts of Russia (Siberia and Ural). While females of chemotype 2 seem to be absent (or at least rare) in Central Russia, we found most females displaying chemotype 2 at Russia's Pacific coast, as well as in Eastern Turkey and in Romania. The two females in our dataset collected in Bulgaria also displayed chemotype 2 (Fig. 3).

\section{Morphometric analysis}

The conducted reliability tests indicated that only 15 of the 16 evaluated characters were measured with consistent accuracy (Supplementary Table S6). Multivariate ratio analysis (MRA) of the 15 characters in 82 females of chemotype 1 and 141 females of chemotype 2 revealed no statistically significant differences between females displaying chemotype 1 and females displaying chemotype 2 (including those with deviant CHC profile) in the four selected populations, neither in size nor in shape axes: Supplementary Fig. S5 shows that groups are largely overlapping. However, we observed that $O$. spinipes females from the Far East of Russia (locality E) are on average slightly larger than females collected in Europe (localities A-D).

\section{Discussion}

\section{Temporal chemical stability of cuticular hydrocarbons}

The results of our study highlight the potential value of drymounted insects stored in private and public collections for chemoecological studies. Our data demonstrate the longterm chemical stability of CHCs. Long-term stability of CHCs had previously been reported by Page et al. (1990) and by Martin et al. (2009) who analyzed samples that were up to 70 and 20 years old, respectively. Since CHCs are typically species-specific in insects (e.g., Soon et al. 2021), their analysis on museum specimens opens the door for inferring the identity of samples (including type material) that 


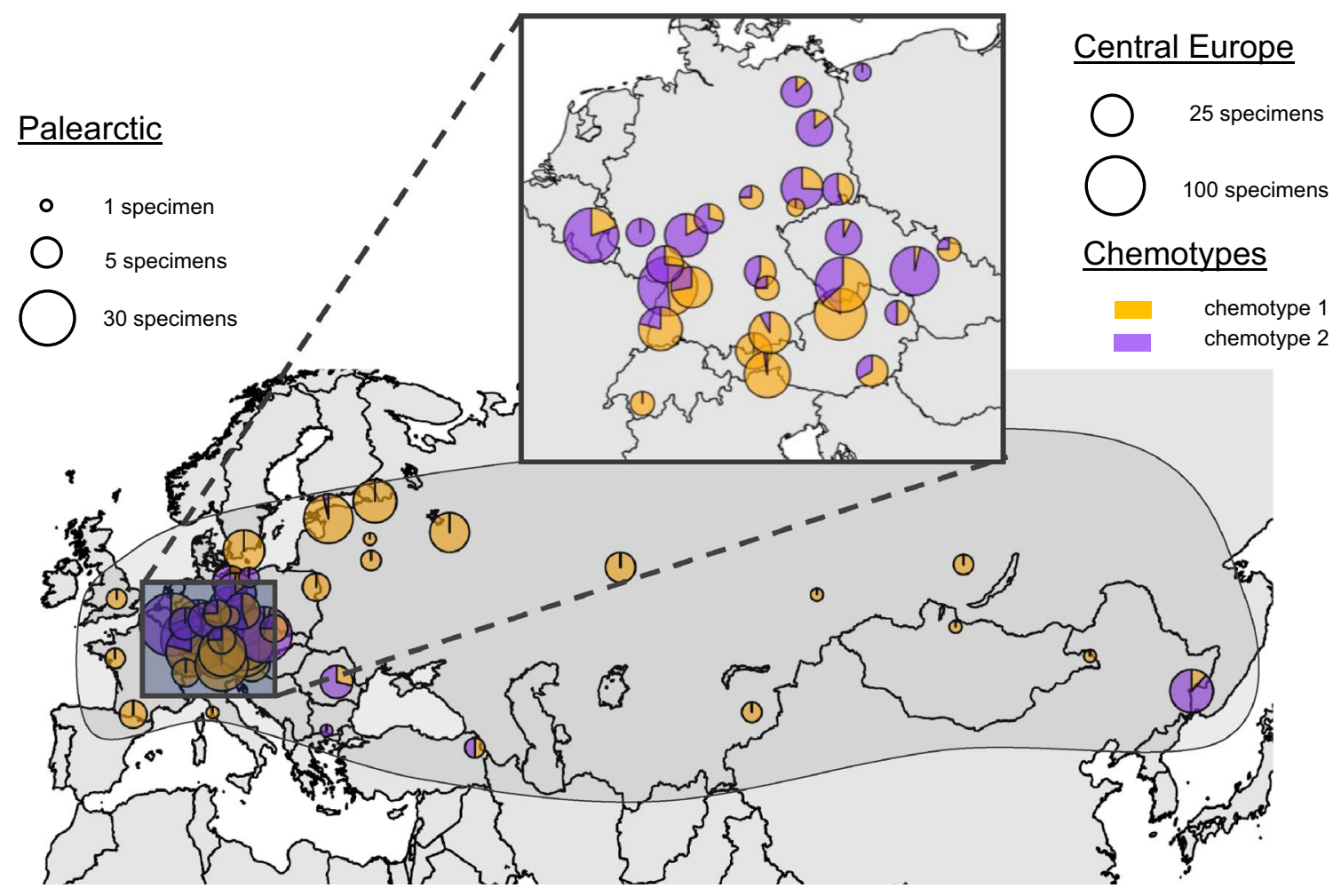

Fig. 3 Geographical differences in the frequency at which Odynerus spinipes females display chemotype 1 (orange) and chemotype 2 (purple). The diameter of the pie charts is proportional to the number of females analyzed from a given location. Note that the pie charts on the two maps have different scales. The approximate distribution of the species is indicated by the continuous black line otherwise could perhaps only be identified using DNA barcoding or not at all. The use of CHCs for identifying cryptic species has been shown in numerous studies (Haverty et al. 1990; Page et al. 1997; Akino et al. 2002; Lucas et al. 2002; Schlick-Steiner et al. 2006; Martin et al. 2008; Guillem et al. 2012; Vaníčková et al. 2014; Soon et al. 2021). And while the ability to study CHCs in dry-mounted insects has been demonstrated in earlier studies (Bartelt et al. 1986; Jallon and David 1987; Grunshawn et al. 1990; Page et al. 1990; Chapman et al. 1995; Everaerts et al. 1997; Clément et al. 2001; Dapporto et al. 2004; Symonds and Elgar 2004; Uva et al. 2004; Dapporto 2007; Hay-Roe et al. 2007; Martin et al. 2008, 2009), these studies relied on samples that had been comparatively recently collected (except that published by Page et al. 1990).

The analysis of CHC extracts of dry-mounted specimens has limitations. First, CHC extracts from such samples have a high chance of being contaminated. While most of the contaminations will likely be volatile non-CHCs, it is imaginable that $\mathrm{CHCs}$ from other samples stored in the same box get transferred over the course of time on the cuticle of samples of interest. Unless fresh material is unavailable, dry-mounted samples should therefore be avoided for de novo characterizing the $\mathrm{CHC}$ profile of a species. If such samples are nonetheless used, the obtained chromatograms should be interpreted with great caution. A second limitation of dry-mounted samples for chemical analyses is the low abundance at which the CHCs are obtained. Since we found in initial tests the trend for longer extraction duration time to increase the yield of $\mathrm{CHCs}$, we recommend future studies on the CHCs of drymounted to extract $\mathrm{CHCs}$ for at least for $10 \mathrm{~min}$. One likely reason for the low amount of $\mathrm{CHCs}$ on dry-mounted samples is evaporation of the insect's CHCs over time, or that the hydrophobic compounds diffuse into the now dried interior of the specimen (Martin et al. 2009). The fact that we successfully extracted $\mathrm{CHC}$ s also from wasps collected a long time ago ( $>100$ years) suggests that the effect of evaporation is likely small, or at least to some extent predictable. A potentially more severe factor than the storage time of the specimen is the kind of chemical used to kill and/or preserve the insects, as some of these chemicals are powerful organic solvents (e.g., carbon tetrachloride, ethanol, diethyl ether, ethyl acetate; Gibb and Oseto 2019). If the insects were killed by being immerged in organic solvent, their CHCs are likely removed very efficiently from the cuticle, since most hydrocarbons are soluble in organic solvents (Krogmann and Holstein 2010; Tewari and Vishnoi 2017). Even if not submerged in solvent, collecting several specimens in the same vial containing an organic 
solvent as killing agent could potentially lead to mixing of CHCs between specimens. We attribute the chemicals used to kill the insects studied by us as the most likely cause of why we were in some instances unable to extract notable quantities of $\mathrm{CHCs}$ regardless of how long ago a sample had been collected.

The most severe problem encountered when studying CHC extracts from old dry-mounted specimens is that the CHC profile of samples can be slightly altered over time. Specifically, we found the CHC profiles of various $O$. spinipes females to contain a mix of $u d p$ and $e d p$ alkenes (same chain length; $23,25,27)$. In contrast, the CHC profiles of freeze-killed specimens consistently contained either $u d p$ alkenes or $e d p$ alkenes. In some females of chemotype 2, we found traces of $u d p$ alkenes, but these alkenes were never as abundant as $e d p$ alkenes of the same chain length (see also results presented by Wurdack et al. 2015). We exclude the possibility that samples with a deviant $\mathrm{CHC}$ profile represent a cryptic species based on the results from the morphometric analyses. We also consider it extremely unlikely that this deviant CHC chemotype 2 represents a third (or intermediate) chemotype, because we found it exclusively in $\mathrm{CHC}$ extracts originating from drymounded samples, some of which collected at locations close to sites where we collected wasps without ever encountering such a deviant profile. We also deem it unlikely that the deviant chemotype got extinct and that its extinction would explain why we did not find it in freshly collected samples. It appears more plausible to us that the $\mathrm{CHC}$ profile of a significant portion of the dry-mounted wasps had changed and that the deviant chemotype 2 is thus an artifact. The specific mechanism(s) that cause(s) this $\mathrm{CHC}$ profile change remain(s) unclear, however. It is known that the volatility of alkenes is generally higher than that of alkanes (including methyl-branched ones) and that the volatility of alkenes differs from each other depending on the molecule's length and the position of the double bond (Gibbs and Pomonis 1995; Tewari and Vishnoi 2017). A difference in volatility between alkanes and alkenes could explain why we always observed alkanes in the studied dry-mounted specimens. Additionally, it is known that alkene double bonds can alter their position by rearrangement reactions and that such reactions can be triggered by light (Tewari and Vishnoi 2017), which might have happened in insect boxes where the dry-mounted samples were stored. Finally, it is also possible that the $u d p$ alkenes found in the deviant chemotype 2 came from sources inside the dry-mounted samples. Because of their dryness, it is possible that hexane extracts hydrocarbons also inside the specimens and not only on the cuticle of the specimens as it does when processing freezekilled fresh samples. Incidentally, Martin et al. (2009) also reported a reduction in the quantity of an alkene (c31ene) in $\mathrm{CHC}$ extracts from hornets collected 20 years ago compared to $\mathrm{CHC}$ extracts from freshly collected hornets (Vespa spp.).

\section{Amount and spatial distribution of different CHC chemotypes}

Based on samples from three field sites in Southern Germany, Wurdack et al. (2015) reported $O$. spinipes females to be able to express two different chemotypes and conspecific males to only express one chemotype. The results of our study are fully consistent with these observations, but our conclusions are based on a significantly larger sample size and covers samples collected from a significantly larger fraction of the species' distributional range. However, in contrast to the observations made by Wurdack et al. (2015), we found the frequency of the two chemotypes to geographically vary considerably and to be rarely balanced. Most notably, we found females of both chemotypes to also occur in the Eastern Palearctic at the Pacific coast-the presumed glacial refuge of this Euro-Siberian faunal element.

The chemotype frequency differences in some parts of the distributional range of $O$. spinipes are remarkable, and multiple mechanisms are imaginable that could have given rise to them. Yet, because species population structures are the result of both present and historical processes (Hewitt 1999), it is difficult to disentangle what factors shaped the chemotype frequency differences in different populations and geographic regions in the absence of additional data (e.g., population genetic information). Chemotype frequency differences could be the results of genetic drift (e.g., during range expansion from a single glacial refuge in the Eastern Palearctic), could reflect different routes and times of the colonization of the Western Palearctic, or could be the result of historical differences in the selection pressure for a given chemotype. For example, while we found females displaying chemotype 1 over the whole distributional range of the species, chemotype 1 is the only one found by us expressed by females collected in the UK and western France. It is thus possible that due to genetic drift, the genetic information for expressing chemotype 2 got lost during the colonization of the UK and western France (e.g., due to a founder effect). It is also imaginable that the two chemotypes had different glacial refuges in the Eastern Palearctic and that females expressing chemotype 1 took another dispersal route and cognized Europe earlier than females expressing chemotype 2 . The hypotheses presented here could be assessed with the aid of population genetic analyses.

The idea of different selection pressures having shaped the observed chemotype frequency differences is particularly intriguing, given that the two chemotypes are chemically mimicked by two cuckoo wasp species, each consistently displaying only one chemotype (i.e., Chrysis mediata and Pseudochrysis neglecta) (Wurdack et al. 2015), which occur across most (if not all) of $O$. spinipes' distributional range (Kimsey and Bohart 1991; Yildırım and Strumia 2006; Kurzenko and Lelej 2007; Rosa et al. 2014; Belokobylskij 
and Lelej 2017; Rosa 2019). Population genetic studies on $O$. spinipes and its kleptoparasitic cuckoo wasps could help disentangling the above factors for having shaped geographic chemotype frequency differences. The presented data provide important information where to geographically preferentially sample $O$. spinipes for such population genetic analyses. They also set the base for investigations that aim at understanding the genetics of the astounding qualitative $\mathrm{CHC}$ profile dimorphism that $O$. spinipes females exhibit.

Supplementary Information The online version contains supplementary material available at https://doi.org/10.1007/s00049-021-00350-8.

Acknowledgements We are indebted to Fritz Gusenleitner, Rolf Franke, Lukas Kirschey, Lars Krogmann, Andrew Liston, Mikhail Mokrousov, Michael Ohl, Patricia Peters, Karl-Heinz Schmalz, Christian Schmid-Egger, Stefan Schmidt, Martin Schwarz, and Dominique Zimmermann for providing us samples and granting permission to chemically analyze them. We acknowledge Paolo Rosa and Manuela Sann for bringing us in contact with some entomologists and JeanYves Baugnée for providing information where to collect $O$. spinipes in Belgium. We are thankful to Rainer Blum for help with georeferencing samples, and to Wolf Haberer for help using the GC-MS. We also thank Nicolas Brasero and Baptiste Martinet for providing their GC to run SPME fibers in Belgium (UMONS). ON and VM acknowledge the Struktur- und Genehmigungsbehörde Süd and the Struktur- und Genehmigungsdirektion Nord (both Rhineland Palatinate) for granting permission to collect samples. Part of the present study were funded by the German Research Foundation (DFG NI1387/2-1, SCHM 2645/6-1). This work was in part supported by the Russian Foundation for Basic Research (project No. 19-04-00027) and Russian State Research Project No. AAAA-A19-119020690101-6 for SAB.

Funding Open Access funding enabled and organized by Projekt DEAL.

Open Access This article is licensed under a Creative Commons Attribution 4.0 International License, which permits use, sharing, adaptation, distribution and reproduction in any medium or format, as long as you give appropriate credit to the original author(s) and the source, provide a link to the Creative Commons licence, and indicate if changes were made. The images or other third party material in this article are included in the article's Creative Commons licence, unless indicated otherwise in a credit line to the material. If material is not included in the article's Creative Commons licence and your intended use is not permitted by statutory regulation or exceeds the permitted use, you will need to obtain permission directly from the copyright holder. To view a copy of this licence, visit http://creativecommons.org/licenses/by/4.0/.

\section{References}

Akino T, Terayama M, Wakamura S, Yamaoka R (2002) Intraspecific variation of cuticular hydrocarbon composition in Formica japonica Motschoulsky (Hymenoptera: Formicidae). Zool Sci 19:1155-1165

Baur H, Leuenberger C (2020) Multivariate Ratio Analysis (MRA): R-scripts and tutorials for calculating Shape PCA, Ratio Spectra and LDA Ratio Extractor (Version 1.02). Zenodo. https://doi.org/ 10.5281/zenodo.3892267

Bagnères A-G, Wicker-Thomas C (2010) Chemical taxonomy with hydrocarbons. In: Blomquist GJ, Bagnères A-G (eds) Insect hydrocarbons. Biology, biochemistry, and chemical ecology. Cambridge University Press, Cambridge, pp 121-162

Bartelt RJ, Armold MT, Schaner AM, Jackson LL (1986) Comparative analysis of cuticular hydrocarbons in the Drosophila virilis species group. Comp Biochem Phys B 83:731-742

Baur H, Leuenberger C (2011) Analysis of ratios in multivariate morphometry. Sys Biol 60:813-825

Bechshøft TØ, Rigét FF, Wiig Ø, Sonne C (2008) Fluctuating asymmetry in metric traits; a practical example of calculating asymmetry, measurement error, and repeatability. Ann Zool Fenn 45:32-38

Belokobylskij SA, Lelej AS (2017) Annotated Catalogue of the Hymenoptera of Russia, volume I, Symphyta and Apocrita: Aculeata. Proceedings ZIN 321:1-475

Blomquist CJ, Bagnères A-G (2010) Insect hydrocarbons. Biology, biochemistry, and chemical ecology. Cambridge University Press, Cambridge

Carlson DA, Roan CS, Yost RA, Hector J (1989) Dimethyl disulfide derivatives of long chain alkenes, alkadienes, and alkatrienes for gas chromatography/mass spectrometry. Anal Chem 61:1564-1571

Chapman RF, Espelie KE, Sword GA (1995) Use of cuticular lipids in grasshopper taxonomy: A study of variation in Schistocerca shoshone (Thomas). Biochem Syst Ecol 23:383-398

Clément J-L, Bagnères A-G, Uva P, Wilfert L, Quintana A, Reinhard J, Dronnet S (2001) Biosystematics of Reticulitermes termites in Europe: morphological, chemical and molecular data. Insectes Soc 48:202-215

Cuvillier-Hot V, Cobb M, Malosse C, Peeters C (2001) Sex, age and ovarian activity affect cuticular hydrocarbons in Diacamma ceylonense, a queenless ant. J Insect Physiol 47:485-493

Dapporto L (2007) Cuticular lipid diversification in Lasiommata megera and Lasiommata paramegaera: the influence of species, sex, and population (Lepidoptera: Nymphalidae). Biol J Linn Soc 91:703-710

Dapporto L, Palagi E, Turillazzi S (2004) Cuticular hydrocarbons of Polistes dominulus as a biogeographic tool: a study of populations from the Tuscan Archipelago and surrounding areas. J Chem Ecol 30:2139-2151

de Lattin G (1967) Grundriss der Zoogeographie. G. Fischer, Stuttgart

De Oliveira CC, Manfrin MH, de M Sene F, Jackson LL, Etges WJ, (2011) Variations on a theme: diversification of cuticular hydrocarbons in a clade of cactophilic Drosophila. BMC Evol Biol $11: 179$

Dobson AJ (1990) An introduction to generalized linear models. Chapman and Hall, London

Dunkelblum E, Tan TS, Silk PJ (1985) Double-bond location in monounsaturated fatty-acids by dimethyl disulfide derivatization and mass-spectrometry-application to analysis of fattyacids in pheromone glands of four Lepidoptera. J Chem Ecol 11:265-277

Everaerts CL, Farine JP, Brossut R (1997) Changes of species specific cuticular hydrocarbon profiles in the cockroaches Nauphoeta cinerea and Leucophaea maderae reared in heterospecific groups. Entomol Exp Appl 85:145-150

Gerritsen H (2013) mapplots: data visualisation on maps. R package version 1.4. http://CRAN.R-project.org/package $=$ mapplots. Accessed 1 Oct 2020

Gibb TJ, Oseto C (2019) Insect collection and identification: techniques for the field and laboratory. Academic Press

Gibbs AG, Pomonis JG (1995) Physical properties of insect cuticular hydrocarbons: The effects of chain length, methyl-branching and unsaturation. Comp Biochem Phys A 112B:243-249

Gibson GAP (1997) Morphology and Terminology. In: Gibson GAP, Huber JT, Woolley JB (eds) Annotated keys to the genera of 
nearctic Chalcidoidea (Hymenoptera). NRC Research Press, Ottawa, pp 16-44

Greene MJ, Gordon DM (2003) Cuticular hydrocarbons inform task decisions. Nature 423:32-32

Grunshawn JP, Guermouche H, Guermouche S, Jago ND, Jullien R, Knowles E, Perez F (1990) Chemical taxonomic studies of cuticular hydrocarbons in locusts of the Schistocerca americana complex: chemical relationships between New World and Old World species. J Chem Ecol 16:2835-3858

Guillem RM, Drijfhout FP, Martin SJ (2012) Using chemo-taxonomy of host ants to help conserve the large blue butterfly. Biol Conserv 148:39-43

Gusenleitner J (1998) Bestimmungstabellen mittel-und südeuropäischer Eumeniden (Vespoidea, Hymenoptera) Teil 8. Die Gattungen Odynerus LATREILLE 1802, Gymnomerus BLÜTHGEN 1938, Paragymnomerus BLÜTHGEN 1938 und Tropidodynerus BLÜTHGEN 1939. Linzer biol Beitr:163-181

Haverty MI, Nelson LJ, Page M (1990) Cuticular hydrocarbons of four populations of Coptotermes formosanus Shiraki in the United States. J Chem Ecol 16:1635-1647

Hay-Roe MM, Lamas G, Nation JL (2007) Pre-and postzygotic isolation and Haldane rule effects in reciprocal crosses of Danaus erippus and Danaus plexippus (Lepidoptera: Danainae), supported by differentiation of cuticular hydrocarbons, establish their status as separate species. Biol J Linn Soc 91:445-453

Hewitt GM (1999) Post-glacial re-colonization of European biota. Biol J Linn Soc 68:87-112

Howard RW, Blomquist GJ (2005) Ecological, behavioral, and biochemical aspects of insect hydrocarbons. Ann Rev Entomol 50:371-393

Hugo LE, Kay BH, Eaglesham GK, Holling N, Ryan PA (2006) Investigation of cuticular hydrocarbons for determining the age and survivorship of Australasian mosquitoes. Am J Trop Med Hyg 74:462-474

Ichinose K, Lenoir A (2009) Ontogeny of hydrocarbon profiles in the ant Aphaenogaster senilis and effects of social isolation. C R Biol 332:697-703

Jackson DE, Martin SJ, Ratnieks FL, Holcombe M (2007) Spatial and temporal variation in pheromone composition of ant foraging trails. Behav Ecol 18:444-450

Jallon JM, David JR (1987) Variation in the cuticular hydrocarbons among the eight species of Drosophila melanogaster subgroup. Evolution 41:294-302

Kimsey LS, Bohart RM (1991) The chrysidid wasps of the world. Oxford Press, New York, p 652

Korb J (2018) Chemical fertility signaling in termites: idiosyncrasies and commonalities in comparison with ants. J Chem Ecol 44:818-826

Krogmann L, Holstein J (2010) Preserving and specimen handling. In: Eymann J, Degreef J, Häuser CL, Monje JC, Samyn Y, VandenSpiegel D (eds) Manual on field recording techniques and protocols for All Taxa Biodiversity Inventories (ATBIs), Part 2, United Kingdom: ABC Taxa, pp 463-481

Kuo TH, Yew JY, Fedina TY, Dreisewerd K, Dierick HA, Pletcher SD (2012) Aging modulates cuticular hydrocarbons and sexual attractiveness in Drosophila melanogaster. J Exp Biol 215:814-821

Kurzenko NV, Lelej AS (2007) Fam. Chrysididae-Chrysidid wasps. In: Lelej AS (ed) Key to the insect of Russian Far East, vol 4, Part 5. Dalnauka, Vladivostok, pp 998-1006

László Z, Baur H, Tóthmérész B (2013) Multivariate ratio analysis reveals Trigonoderus pedicellaris Thomson (Hymenoptera, Chalcidoidea, Pteromalidae) as a valid species. Syst Entomol 38:753-762

Liang D, Silverman J (2000) "You are what you eat": diet modifies cuticular hydrocarbons and nestmate recognition in the
Argentine ant, Linepithema humile. Naturwissenschaften $87: 412-416$

Linsenmaier W (1951) Die europäischen Chrysididen (Hymenoptera). Versuch einer natürlichen Ordnung mit Diagnosen. Mitt Schweiz Entomol Ges 24:1-110

Lucas C, Fresneau D, Kolmer K, Heinze J, Delabie JH, Pho DB (2002) A multidisciplinary approach to discriminating different taxa in the species complex Pachycondyla villosa (Formicidae). Biol J Linn Soc 75:249-259

Marten A, Kaib M, Brandl R (2009) Cuticular hydrocarbon phenotypes do not indicate cryptic species in fungus-growing termites (Isoptera: Macrotermitinae). J Chem Ecol 35:572-579

Martin SJ, Drijfhout FP (2009) Nestmate and task cues are influenced and encoded differently within ant cuticular hydrocarbon profiles. J Chem Ecol 35:368-374

Martin SJ, Helanterae H, Drijfhout FP (2008) Evolution of speciesspecific cuticular hydrocarbon patterns in Formica ants. Biol J Linn Soc 95:131-140

Martin SJ, Zhong W, Drijfhout FP (2009) Long-term stability of hornet cuticular hydrocarbons facilitates chemotaxonomy using museum specimens. Biol J Linn Soc 96:732-737

Martin SJ, Carruthers JM, Williams PH, Drijfhout FP (2010) Host specific social parasites (Psithyrus) indicate chemical recognition system in bumblebees. J Chem Ecol 36:855-863

Nunes TM, Turatti IC, Lopes NP, Zucchi R (2009) Chemical signals in the stingless bee, Frieseomelitta varia, indicate caste, gender, age, and reproductive status. J Chem Ecol 35:1172-1180

Page M, Nelson LJ, Haverty MI, Blomquist GJ (1990) Cuticular hydrocarbons of eight species of North American cone beetles, Conophthorus Hopkins. J Chem Ecol 16:1173-1198

Page M, Nelson LJ, Blomquist GJ, Seybold SJ (1997) Cuticular hydrocarbons as chemotaxonomic characters of pine engraver beetles (Ips spp.) in the grandicollis subgeneric group. J Chem Ecol 23:1053-1099

Palmer A, Strobeck C (1986) Fluctuating asymmetry: measurement, analysis, patterns. Annu Rev Ecol Evol S 17:391-421

Pauli T, Castillo-Cajas RF, Rosa P, Kukowka S, Berg A, van den Berghe E, Fornoff F, Hopfenmüller S, Niehuis M, Peters RS, Staab M, Strumia F, Tischendorf S, Schmitt T, Niehuis O (2019) Phylogenetic analysis of cuckoo wasps (Hymenoptera: Chrysididae) reveals a partially artificial classification at the genus level and a species-rich clade of bee parasitoids. Syst Entomol 44:322-335

Pauli T, Meusemann K, Kukowka S, Sann M, Donath A, Mayer C, Oeyen JP, Ballesteros Y, Berg A, van den Berghe E, Escalona HE, Guglielmino A, Niehuis M, Olmi M, Podsiadlowski L, Polidori C, de Rond J, Rosa P, Schmitt T, Strumia F, Wurdack M, Liu S, Zhou X, Misof B, Peters RS, Niehuis O (2021) Analysis of RNAseq, DNA target enrichment, and Sanger nucleotide sequence data resolves deep splits in the phylogeny of cuckoo wasps (Hymenoptera: Chrysididae). Insect Syst Divers 5:1-14

Polidori C, Giordani I, Wurdack M, Tormos J, Asís JD, Schmitt T (2017) Post-mating shift towards longer-chain cuticular hydrocarbons drastically reduces female attractiveness to males in a digger wasp. J Insect Physiol 100:119-127

R Core Team (2020): A language and environment for statistical computing R Foundation for Statistical Computing, Vienna, Austria. http://www.R-project.org/. Accessed 1 Oct 2020

Rosa P (2019) New remarkable species in the Chrysis ignita group (Hymenoptera, Chrysididae) and an overview on Central Asian species, with new synonymies. Linzer biol Beitr 51:397-417

Rosa P, Wei NS, Xu ZF (2014) An annotated checklist of the chrysidid wasps (Hymenoptera, Chrysididae) from China. ZooKeys 455:1-128

Rosa P, Pavesi M, Soon V, Niehuis O (2017) Pseudochrysis Semenov, 1891 is the valid genus name for a group of cuckoo wasps 
frequently referred to as Pseudospinolia Linsenmaier, 1951 (Hymenoptera, Chrysididae). Deut Entomol Z 64:69-75

Schlick-Steiner BC, Steiner FM, Moder K, Seifert B, Sanetra M, Dyreson E, Stauffer C, Erhard C (2006) A multidisciplinary approach reveals cryptic diversity in Western Palearctic Tetramorium ants (Hymenoptera: Formicidae). Mol Phylogenet Evol 40:259-273

Schneider C, Rasband W, Eliceiri K (2012) NIH Image to ImageJ: 25 years of image analysis. Nat Methods 9:671-675. https://doi.org/ 10.1038/nmeth.2089

Shuckard WE (1837) Description of the genera and species of the British Chrysididae. Entomol Mag 4:156-177

Sledge MF, Boscaro F, Turillazzi S (2001) Cuticular hydrocarbons and reproductive status in the social wasp Polistes dominulus. Behav Ecol Sociobiol 49:401-409

Soon V, Castillo-Cajas RF, Johansson N, Paukkunen J, Rosa P, Ødegaard F, Schmitt T, Niehuis O (2021) Cuticular hydrocarbon profile analyses help clarify the species identity of dry-mounted cuckoo wasps (Hymenoptera: Chrysididae), including type material, and reveal evidence for a cryptic species. Insect Syst Divers $5: 3 ; 1-12$

Strohm E, Herzner G, Kaltenpoth M, Boland W, Schreier P, Geiselhardt S, Peschke K, Schmitt T (2008a) The chemistry of the postpharyngeal gland of female European beewolves. J Chem Ecol 34:575-583

Strohm E, Kroiss J, Herzner G, Laurien-Kehnen C, Boland W, Schreier P, Schmitt T (2008b) A cuckoo in wolves' clothing? Chemical mimicry in a specialized cuckoo wasp of the European beewolf (Hymenoptera, Chrysididae and Crabronidae). Front Zool 5:2

Symonds MR, Elgar MA (2004) The mode of pheromone evolution: evidence from bark beetles. Proc Biol Sci 271:839-846
Tewari KS, Vishnoi NK (2017) A textbook of organic chemistry, 4th edn. Vikas Publishing House

Uva P, Clément J-L, Bagnères A-G (2004) Colonial and geographic variations in agonistic behaviour, cuticular hydrocarbons and mtDNA of Italian populations of Reticulitermes lucifugus (Isoptera, Rhinotermitidae). Insectes Soc 51:163-170

Van Buuren S, Groothuis-Oudshoorn K (2011) Mice: multivariate imputation by chained equations in RJ Stat. J Stat Softw 45:1-67

Vaníčková L, Virgilio M, Tomčala A, Břízová R, Ekesi S, Hoskovec M, Kalinová B, Do Nascimento RR, De Meyeret M (2014) Resolution of three cryptic agricultural pests (Ceratitis fasciventris, $C$. anonae, C. rosa, Diptera: Tephritidae) using cuticular hydrocarbon profiling. Bull Entomol Res 104:631-638

Woydak H (2006) Abhandlungen aus dem Westfälischen Museum für Naturkunde 68. Jahrgang 2006, Heft 1. In: Tenbergen B (ed) Hymenoptera Aculeata Westfalica Die Faltenwespen von Nordrhein-Westfalen (Hymenoptera, Vespoidea; Vespidae und Eumenidae) (Soziale Papier- und Lehmwespen). Landschaftsverband Westfalen-Lippe, Münster, pp 57-60

Wurdack M, Herbertz S, Dowling D, Kroiss J, Strohm E, Baur H, Niehuis O, Schmitt T (2015) Striking cuticular hydrocarbon dimorphism in the mason wasp Odynerus spinipes and its possible evolutionary cause (Hymenoptera: Chrysididae, Vespidae). Proc Biol Sci 282:20151777

Yildırım E, Strumia F (2006) Contribution to the knowledge of Chrysididae fauna of Turkey. Part 3: chrysidinae (Hymenoptera, Chrysididae). Linzer Biol Beitr 39:973-984 